\title{
Brain natriuretic peptide as a diagnostic marker for heart failure in hyperthyroid patients with ischemic heart disease Hazem M. El-Ashmawy ${ }^{a}$, Ekhlas M. Hussein ${ }^{b}$, Azza M. Ahmed ${ }^{c}$
}

Departments of anternal Medicine,

${ }^{\mathrm{b} C}$ Cardiology, ${ }^{\mathrm{C}}$ Clinical Pathology, Faculty of Medicine, Zagazig University, Zagazig, Egypt

Correspondence to Hazem M. El-Ashmawy, MD, Internal Medicine Department, Faculty of Medicine, Endocrinology Unite, Zagazig

University, Sharkyia Governorate, Zagazig City, 44519, Egypt. Tel: +20 122370 7087; fax: +20552368567;

e-mail: hazemashmawy@zu.edu.eg

Received 8 November 2017

Accepted 12 December 2017

The Egyptian Journal of Internal Medicine 2018, 30:63-67

\begin{abstract}
Objective
The aim of the study was to evaluate the value of the N-terminal prohormone of brain natriuretic peptide (NT-proBNP) as an early diagnostic marker for chronic heart failure (CHF) in hypothyroid patients with ischemic heart disease (IHD).

Materials and methods

A total of 120 patients with an age range between 42 and 64 years participated in the study. All patients were classified into four groups: the master first group includes 30 patients with IHD, CHF functional class II-III and hyperthyroidism; the second group includes 30 patients with IHD and CHF functional class II-III, but with normal thyroid function; the third group includes 30 hyperthyroid patients without $\mathrm{CHF}$ or IHD; and the fourth group includes 30 hyperthyroid patients with IHD, without CHF. All patients were subjected to the following: full clinical and functional assessment, measurement of NT-proBNP, echocardiography, and the 6-min walk test.

Results

NT-proBNP levels were high in all studied groups. NT-proBNP levels showed no significant difference between patients of second and fourth group. The master first group had the highest significant NT-proBNP concentrations than other studied groups. Thyroid hyperfunction in patients with IHD appears to stimulate the natriuretic peptides secretion at a level exceeding what is recommended for the initial diagnosis of CHF.

Conclusion

The highest NT-proBNP level in hyperthyroid patients with IHD apparently is caused by stimulation of natriuretic peptide secretion by both thyroid hyperfunction and myocardial ischemic changes, which determine the need to check out the cut-off value of NT-proBNP level as a serological marker for the initial diagnosis of heart failure of such patients' category.
\end{abstract}

\section{Keywords:}

brain natriuretic peptide, chronic heart failure, hyperthyroidism, ischemic heart disease

Egypt J Intern Med 30:63-67

(C) 2018 The Egyptian Journal of Internal Medicine $1110-7782$

\section{Introduction}

An estimated 37.7 million individuals are living with heart failure (HF) worldwide [1]. The worldwide incidence of $\mathrm{HF}$ ranges from 100 to 900 patients for each 100000 individual per year, relying on the criteria of diagnosis used and community studied [2]. Epidemiological studies carried out in developing countries have determined the risk factors and etiologies for HF, but no further detailed epidemiological data were available [3,4]. Ischemic heart disease (IHD) is one of the most important risk factor for $\mathrm{HF}[5,6]$. One of the most urgent problems at present is the combination of cardiovascular pathology with other diseases. The number of patients with multimorbidity significantly increases with age, reaching up to $78 \%$ in people 80 years of age and older [7]. Often in patients of middle and older age groups, there is a combination of IHD and thyroid hyperfunction, with the prevalence of the thyrotoxicosis range from 0.5 to $3.9 \%$, which is most often in women [8-10]. Considering the mutual influence of hyperthyroidism and cardiovascular pathology such as chronic heart failure (CHF) and IHD, it is necessary to take into account their combination when choosing methods for diagnosis and treatment tactics. According to the recommendations of the European Society of Cardiology (ESC) (2016), the most important early diagnosis of $\mathrm{CHF}$ is the defining the level of brain natriuretic peptide (BNP) or N-terminal fragment of the precursor BNP (NT-proBNP), especially in $\mathrm{HF}$ patients with persistent and midrange ejection fraction (HFmrEF) of the left ventricle (LV) [11]. $\mathrm{BNP}$ and NT-proBNP are strong prognostic markers of IHD [12] or HF [13]. The maximum limit of normal in chronic settings for NT-proBNP is $125 \mathrm{pg} / \mathrm{ml}$. Plasma levels of NT-proBNP less than

This is an open access journal, and articles are distributed under the terms of the Creative Commons Attribution-NonCommercial-ShareAlike 4.0 License, which allows others to remix, tweak, and build upon the work non-commercially, as long as appropriate credit is given and the new creations are licensed under the identical terms. 
$125 \mathrm{pg} / \mathrm{ml}$ make the diagnosis of HF unlikely [11]. The literature data show that the level of NT-proBNP is affected by changes in thyroid hormone levels. A number of researchers noted that an increase in thyroid hormone levels in the serum provoked an increased production of natriuretic peptides, in particular NT-proBNP [14]. Serum level of NTproBNP may increase with thyrotoxicosis, regardless of the presence of $\mathrm{HF}$, which is probably related to direct stimulating action of thyroid hormones [15]. On the contrary, thyrotoxicosis can lead to structural changes in the heart, undetectable with conventional echocardiography, and these changes may be responsible for raising the level of NT-proBNP [14]. Many studies have reported on the efficacy of using NT-proBNP level as a diagnostic marker for detection of CHF [16-18]. The controversial judgments about the effect of thyroid hormones on the level of NTproBNP determine the need for further studies for the causes of its increase in the serum of hyperthyroid patients with IHD. It is of interest to estimate the effect of increased level of thyroid hormones for secretion of NT-proBNP and the possibility of using this marker for the diagnosis of $\mathrm{CHF}$ on the background of IHD and hyperthyroidism. The aim of this study was to evaluate the value of the BNP as an early marker for the diagnosis of $\mathrm{HF}$ in patients with IHD and hyperthyroidism.

\section{Materials and methods}

The study included 120 patients who were admitted at Cardiology and Endocrinology Departments of the University Hospital, Egypt. All patients were classified into four groups: the master first group: 30 patients with hyperthyroidism, IHD, and CHF functional class (FC) II-III; the second group: 30 patients with IHD and CHF FC II-III, but without thyroid dysfunction; the third group: 30 patients with hyperthyroidism but without IHD or CHF; and the fourth group: 30 patients with hyperthyroidism and IHD, without CHF. Patients with IHD FC II-III were selected according to the Canadian Cardiovascular Society grading of angina pectoris [19]. Diagnosis and treatment of IHD and CHF were conducted in accordance with modern standards and recommendations [11,20]. Hypertensive patients were classified according to $2013 \mathrm{ESH} / \mathrm{ESC}$ guidelines for the management of arterial hypertension [21]. Patients with CHF FC II-III were selected according to the New York Heart Association Functional Classification [22]; in addition, full clinical and functional assessments were carried out to determine the tolerability of physical load used in 6-min walk test [23]. The indices of free tri-iodothyronine (FT3), free tetraiodothyronine (FT4), and Thyroid stimulating hormone (TSH) were determined by radioimmunological method. The NT-proBNP level was determined by an enzyme immunoassay for quantifying NT-proBNP in human serum on the automatic enzyme immunoassay analyzer. The exclusion criteria for the study were hemodynamically significant heart diseases (congenital, acquired), pericarditis, myocarditis, acute myocardial infarction or acute cerebral infarction, advanced diseases of the liver or kidneys (glomerular filtration rate $<30 \mathrm{ml} / \mathrm{min} / 1.73 \mathrm{~m}^{2}$ ), and the presence of artificial pacemaker, inflammatory or infectious diseases, and malignant neoplasms.

All patients signed an informed consent to participate in the study. Statistical processing of receiving data was conducted using the program (SPSS V.20; SPPS Inc., Chicago, Illinois, USA). $P$ value less than 0.05 was considered significant.

\section{Results and discussion}

The results of the study showed that the BMI and age in the group of patients with hyperthyroidism without CHF or IHD (third group) were significantly lower $(P<0.05)$ in comparison with the master first group, the second group, and the fourth group. This finding is concurrent with the literature studies, which confirm that overweight, obesity, and advanced aging are directly related to the development and progression of cardiovascular diseases including IHD and CHF [24-29]. Clinical characteristics and parameters of the thyroid hormonal profile for all participants are presented in Table 1. When analyzing the level of thyroid hormones in patients of the master first, third, and fourth group, there were no significant differences between them. However, the duration of hyperthyroidism was the longest in patients of the master first group $6.7 \pm 0.45$ months, exceeding by 2.4 and 2.5 times than in the third and fourth group, respectively. It can be assumed that the reason was the severity of the clinical picture on the background of cardiovascular morbidity of the master first group, prompting initially to seek medical consultation with early diagnosis of the hyperthyroid status. The heart rate in the master first group as well as in the third and fourth group (i.e. patients with hyperthyroidism) was significantly higher $(P<0.05)$ than in the second group, which was probably a consequence of the stimulating effect of thyroid hormones on the sympathetic nervous system. It is important to 
Table 1 Clinical characteristics and parameters of the thyroid hormonal spectrum for all groups $(n=120)$

\begin{tabular}{|c|c|c|c|c|}
\hline \multirow[t]{2}{*}{ Groups } & \multicolumn{4}{|c|}{ Index } \\
\hline & Master first group $(n=30)$ & $\begin{array}{l}\text { Second group } \\
(n=30)\end{array}$ & Third group $(n=30)$ & Fourth group $(n=30)$ \\
\hline BMI $\left(\mathrm{kg} / \mathrm{m}^{2}\right)($ mean $\pm \mathrm{SD})$ & $\begin{array}{l}27.38 \pm 2.75 ; P_{2}>0.05 \\
\quad P_{3}<0.05 ; P_{4}>0.05\end{array}$ & $27.62 \pm 2.28$ & $\begin{array}{c}23.24 \pm 1.80 \\
P_{2}=0.01\end{array}$ & $\begin{array}{c}26.92 \pm 3.11 ; P_{2}>0.05 ; \\
P_{3}<0.05\end{array}$ \\
\hline Male $[n(\%)]$ & $13(43.3)$ & $14(46.6)$ & $12(40.0)$ & $11(36.6)$ \\
\hline Female $[n(\%)]$ & $17(56.6)$ & $16(53.3)$ & $18(60.0)$ & $19(63.3)$ \\
\hline Age (years) $($ mean $\pm S D)$ & $\begin{array}{c}58.74 \pm 3.22 ; P_{2}>0.05 \\
\quad P_{3}<0.05 ; P_{4}>0.05\end{array}$ & $57.33 \pm 3.61$ & $44.9 \pm 2.72 ; \mathrm{P}_{2}<0.05$ & $\begin{array}{c}58.88 \pm 3.14 ; P_{2}>0.05 ; \\
P_{3}<0.05\end{array}$ \\
\hline $\begin{array}{l}\text { Mean heart rate }(\mathrm{bpm}) \\
(\text { mean } \pm \text { SD) }\end{array}$ & $\begin{array}{c}91 \pm 9 ; P_{2}<0.05 \\
P_{3}>0.05 \\
P_{4}>0.05\end{array}$ & $72 \pm 9$ & $94 \pm 8 ; \mathrm{P}_{2}<0.05$ & $\begin{array}{c}95 \pm 8 ; P_{2}<0.05 \\
P_{3}>0.05\end{array}$ \\
\hline $\mathrm{AH}[n(\%)]$ & $26(86.6)$ & $19(63.3)$ & $12(40)$ & $18(60)$ \\
\hline Grade 1 & $7(26.9)$ & $6(31.5)$ & $9(75)$ & $10(55.5)$ \\
\hline Grade 2 & $14(53.8)$ & $11(57.8)$ & $3(25)$ & $6(33.3)$ \\
\hline Grade 3 & 5 (19.2) & $2(10.5)$ & - & $2(11.1)$ \\
\hline $\begin{array}{l}\text { AH duration (years) } \\
(\text { mean } \pm \text { SD) }\end{array}$ & $4.26 \pm 0.51$ & $4.2 \pm 0.42$ & First detected & $3.25 \pm 0.54$ \\
\hline \multicolumn{5}{|l|}{ IHD (CCS) [n (\%)] } \\
\hline FC I & - & - & - & - \\
\hline FC II & $8(26.6)$ & $10(30)$ & - & $11(36.6)$ \\
\hline FC III & $22(73.3)$ & $20(70)$ & - & 19 (63.3) \\
\hline FC IV & - & - & - & - \\
\hline $\begin{array}{l}\text { IHD duration, (years) } \\
(\text { mean } \pm S D)\end{array}$ & $5.3 \pm 1.2 ; P_{2}>0.05 ; P_{4}>0.05$ & $5.5 \pm 0.67$ & - & $4.29 \pm 0.93 ; P_{2}>0.05$ \\
\hline Previous MI $[n(\%)]$ & $16(53.3)$ & $22(73.3)$ & - & 7 (23.3) \\
\hline \multicolumn{5}{|l|}{ CHF (NYHA) [n (\%)] } \\
\hline FC II & $16(53.3)$ & $20(66.6)$ & & - \\
\hline FC III & $14(46.6)$ & $10(33.3)$ & - & - \\
\hline $\mathrm{TSH}(\mathrm{mlU} / \mathrm{l})(\mathrm{mean} \pm \mathrm{SD})$ & $\begin{array}{c}0.02 \pm 0.09 ; P_{2}<0.05 \\
P_{3}>0.05 ; P_{4}>0.05\end{array}$ & $1.64 \pm 0.95$ & $0.02 \pm 0.06 ; \mathrm{P}_{2}<0.05$ & $\begin{array}{c}0.03 \pm 0.05 ; P_{2}<0.05 \\
P_{3}>0.05\end{array}$ \\
\hline FT4 (pmol/l) $($ mean \pm SD $)$ & $\begin{array}{c}41.8 \pm 12.6 ; P_{2}<0.05 \\
P_{3}>0.05 ; P_{4}>0.05\end{array}$ & $14.8 \pm 2.7$ & $42.5 \pm 18.3 ; \mathrm{P}_{2}<0.05$ & $\begin{array}{c}43.6 \pm 16.2 ; P_{2}<0.05 \\
P_{3}>0.05\end{array}$ \\
\hline FT3 (pmol/l) $($ mean \pm SD $)$ & $\begin{array}{l}7.2 \pm 1.4 ; P_{2}<0.05 \\
P_{3}>0.05 ; P_{4}>0.05\end{array}$ & $3.9 \pm 1.3$ & $7.7 \pm 2.1 ; \mathrm{P}_{2}<0.05$ & $\begin{array}{c}6.9 \pm 1.9 ; P_{2}<0.05 \\
P_{3}>0.05\end{array}$ \\
\hline $\begin{array}{l}\text { HT duration (months) } \\
\text { (mean } \pm \mathrm{SD})\end{array}$ & $\begin{array}{c}6.7 \pm 0.45 ; P_{3}<0.05 ; \\
P_{4}<0.05\end{array}$ & - & $2.75 \pm 0.37$ & $2.68 \pm 0.26 ; P_{3}>0.05$ \\
\hline
\end{tabular}

$\mathrm{AH}$, arterial hypertension; CCS, Canadian Cardiovascular Society grading; CHF, chronic heart failure; FC, functional class; FT3, free triiodothyronine; FT4, free tetraiodothyronine; HT, hyperthyroidism; IHD, ischemic heart disease; MI, myocardial infarction; NYHA, New York Heart Association; $P_{2}$, comparison with the second group; $P_{3}$, comparison with the third group; $P_{4}$, comparison with the fourth group; TSH, thyroid stimulating hormone. $P<0.05$, significant.

Table 2 Six-minute walking results in patients with chronic heart failure

\begin{tabular}{lcc}
\hline Groups & \multicolumn{2}{c}{ Index } \\
\cline { 2 - 3 } & Master first group $(n=30)$ & Second group $(n=30)$ \\
\hline 6MWT $(\mathrm{m})$ & $255.93 \pm 15.84 P<0.05$ & $302.35 \pm 20.13$ \\
(mean \pm SD) & & \\
\hline
\end{tabular}

6MWT, 6-minute walk test. $P<0.05$, significant.

emphasize that patients of the master first group, second group, and fourth group were dominated by the FCIII of angina pectoris $(73,70$, and 63 , respectively), but the duration of IHD being comparable in all three compared groups. Exercise tolerance was at the lowest level in the master first group, as the mean average distance walked with this group was $255.93 \pm 15.84$, which is 1.18 times less than in the second group $(P<0.05)$. Lower tolerance to exercise apparently is owing to the presence of concomitant hyperthyroidism in patients of the master first group. Hyperthyroidism is associated with exercise intolerance due to insufficient increase in cardiac output during effort [30-33]. Six-minute walk test results in patients with $\mathrm{CHF}$ are presented in Table 2. The mean left ventricular ejection fraction (LVEF) in the patients of the third and fourth group was within the normal range (66 and $55 \%$, respectively), but it should be noted that a higher value of LVEF was present in the group of patients with hyperthyroidism (third group) compared with other groups $(P<0.05)$, which is known to be a characteristic of the hyperkinetic stage of thyrotoxic heart disease. Hyperthyroidism promotes an increase in myocardial contractility and LV hypertrophy and may develop a 'high-output HF' 
Table 3 The N-terminal prohormone of brain natriuretic peptide level and left ventricular ejection fraction for all groups

\begin{tabular}{lcccc}
\hline Groups & \multicolumn{4}{c}{ Index } \\
\cline { 2 - 5 } & Master first group $(n=30)$ & $\begin{array}{c}\text { Second group } \\
(n=30)\end{array}$ & Third group $(n=30)$ & Fourth group $(n=30)$ \\
\hline Mean NT-proBNP & $713.13(432.25-894.92) ;$ & 325.61 & $254.46(181.14-37.13) ;$ & $346.28(264.75-421.65) ;$ \\
(pg/ml) & $P_{2}<0.05 ; P_{3}<0.05 ; P_{4}<0.05$ & $(254.72-455.67)$ & $P_{2}=0.01$ & $P_{2}>0.05 ; P_{3}<0.05$ \\
Mean LVEF (\%) & $40.0(36.0-43.0) ; P_{2}<0.05 ;$ & $46.0(41.0-47.0)$ & $66.0(61.0-69.0) ;$ & $55.0(52.0-60.0) ;$ \\
& $P_{3}<0.05 ; P_{4}<0.05$ & & $P_{2}<0.05$ & $P_{2}<0.05 ; P_{3}<0.05$ \\
\hline
\end{tabular}

LVEF, left ventricular ejection fraction; NT-proBNP, N-terminal prohormone of brain natriuretic peptide; $P_{2}$, comparison with the second group; $P_{3}$, comparison with the third group; $P_{4}$, comparison with the fourth group. $P<0.05$, significant.

[34-36]. However, the risk of developing HF with a low ejection fraction increases in elderly hyperthyroid patients with concomitant IHD and arterial hypertension [32]. Analysis of indices of LVEF in patients of the second group and the master first group indicates a decrease in contractility of the LV in the conditions of development and progression of CHF. In patients of the second group who have IHD and CHF, LVEF was significantly lower (46\%), than in the third and fourth group $(P<0.05)$, but within LVEF range from 40 to $49 \%$, which corresponds to $\mathrm{HF}$ with midrange EF (HFmrEF) type of cardiac insufficiency (ESC guidelines, 2016) [11]. Patients with $\mathrm{CHF}$ associated with IHD and hyperthyroidism (the master first group) have the lowest significant LVEF, $40.0 \%(36.0-43)$ in relation to the other studied groups $(P<0.05)$. The NT-proBNP level and LVEF for all studied groups are presented in Table 3. There was an elevated level of NT-proBNP in all groups included in the study. The level of NT-proBNP in the group of patients with hyperthyroidism without CHF and IHD (third group) was 2.8 times lower than in patients of the master first group, but it exceeded the established cut-off value of $125 \mathrm{pg} / \mathrm{ml}$ for NT-proBNP as an initial diagnostic test according to the recommendations of ESC (2016) [11]. No significant difference was found between patients with IHD and CHF (second group) and those with IHD and hyperthyroidism but without CHF (fourth group) regarding the level of NT-proBNP $(P>0.05)$, but both groups were 2.19 and 2.06 times, respectively, significantly lower in comparison with the master first group $(P<0.05)$, which allows one to think about the additive effects of morphological and functional changes of the LV and hyperproduction of thyroid hormones on the mean level of NT-proBNP, which was at the highest concentration in patients of the master first group, $713.13 \mathrm{pg} / \mathrm{ml}$ (432.25-894), probably owing to the influence of both factors together on the secretion of the NT-proBNP.The study confirms the importance of determining the diagnostic level of NT-proBNP for the detection of
CHF in case of patients with IHD with thyroid hyperfunction.

\section{Conclusion}

In patients with IHD and hyperthyroidism, the recommended plasma level of NT-proBNP $(125 \mathrm{pg} / \mathrm{ml})$ cannot be used as an initial diagnostic criterion of $\mathrm{CHF}$, and further studies are needed for determining the optimal level of initial diagnosis in such group of patients.

\section{Acknowledgements}

The authors thank all the staff in the Faculty of Medicine, Zagazig University, for their assistance in conducting this study.

\section{Financial support and sponsorship} Nil.

\section{Conflicts of interest}

There are no conflicts of interest.

\section{References}

1 Vos T, Flaxman AD, Naghavi M, Lozano R, Michaud C, Ezzati M, et al. Years lived with disability (YLDs) for 1160 sequelae of 289 diseases and injuries 1990-2010: a systematic analysis for the Global Burden of Disease Study 2010. Lancet 2013; 380:2163-2196.

2 Roger VL. Epidemiology of heart failure. Circ Res 2013; 113: 646-659.

3 Stewart S, Wilkinson D, Hansen C, Vaghela V, Mvungi R, McMurray J, et al. Predominance of heart failure in the Heart of Soweto Study cohort: emerging challenges for urban African communities. Circulation 2008; 118:2360-2367.

4 Bloomfield GS, Barasa FA, Doll JA, Velazquez EJ. Heart failure in subSaharan Africa. Curr Cardiol Rev 2013; 9:157-173.

5 Kenchaiah S, Narula J, Vasan RS. Risk factors for heart failure. Med Clin North Am 2004; 88:1145-1172.

6 Loehr LR, Rosamond WD, Chang PP, Folsom AR, Chambless LE. Heart failure incidence and survival (from the Atherosclerosis Risk in Communities study). Am J Cardiol 2008; 101:1016-1022.

7 Van den Akker M, Buntinx F, Metsemakers JF, Roos S, Knottnerus JA. Multimorbidity in general practice: prevalence, incidence, and determinants of co-occurring chronic and recurrent diseases. J Clin Epidemiol 1998; 51:367-375.

8 Tunbridge WM, Evered DC, Hall R, Appleton D, Brewis M, Clark F, et al. The spectrum of thyroid disease in a community: the Whickham survey. Clin Endocrinol (Oxf) 1977; 7:481-493.

9 Sawin CT, Castelli WP, Hershman JM, McNamara P, Bacharach P. The aging thyroid. Thyroid deficiency in the Framingham study. Arch Intern Med 1985; 145:1386-1388. 
$10 \mathrm{Nw}$ S, Ew G. Serum thyrotropin, thyroxine, and thyroid antibodies in the United States population (1988 to 1994): NHANES III. J Clin Endocrinol Metab 2002; 87:489-499.

11 Ponikowski $\mathrm{P}$, Voors AA, Anker SD, Bueno H, Cleland JG, Coats AJ, et al. 2016 ESC Guidelines for the diagnosis and treatment of acute and chronic heart failure: The Task Force for the diagnosis and treatment of acute and chronic heart failure of the European Society of Cardiology (ESC) Developed with the special contribution of the Heart Failure Association (HFA) of the ESC. Eur Heart J 2016; 37:2129-2200.

12 Farmakis D, Filippatos G, Tubaro M, Peacock WF, Disomma S, Mueller C et al. Natriuretic peptides in acute coronary syndromes: prognostic value and clinical implications. Congest Heart Fail 2008; 14:25-29.

13 Doust JA, Pietrzak E, Dobson A, Glasziou P. How well does B-type natriuretic peptide predict death and cardiac events in patients with heart failure: systematic review. BMJ 2005; 330:625.

14 Wei T, Zeng C, Tian Y, Chen Q, Wang L. B-type natriuretic peptide in patients with clinical hyperthyroidism. J Endocrinol Invest 2005; 28:8-11.

15 Schultz M, Faber J, Kistorp C, Jarlov A, Pedersen F, Wiinberg N, et al. Nterminal-pro-B-type natriuretic peptide (NT-pro-BNP) in different thyroid function states. Clin Endocrinol (Oxf) 2004; 60:54-59.

16 Hobbs F, Davis R, Roalfe A, Hare R, Davies M, Kenkre J. Reliability of Nterminal pro-brain natriuretic peptide assay in diagnosis of heart failure: cohort study in representative and high risk community populations. BM 2002; 324:1498.

17 Richards AM, Nicholls MG, Yandle TG, Frampton C, Espiner EA, Turner JG et al. Plasma N-terminal pro-brain natriuretic peptide and adrenomedullin. Circulation 1998; 97:1921-1929.

18 Talwar S, Squire I, Downie P, McCullough A, Campton M, Davies J, et al. Profile of plasma N-terminal proBNP following acute myocardial infarction. Correlation with left ventricular systolic dysfunction. Eur Heart J 2000 21:1514-1521.

19 Campeau L. The Canadian Cardiovascular Society grading of angina pectoris revisited 30 years later. Can J Cardiol 2002; 18:371-379.

20 Fihn SD, Blankenship JC, Alexander KP, Bittl JA, Byrne JG, Fletcher BJ et al. 2014 ACC/AHA/AATS/PCNA/SCAI/STS focused update of the guideline for the diagnosis and management of patients with stable ischemic heart disease. Circulation 2014; 64:1929-1949.

21 Council ES, Redon J, Narkiewicz K, Nilsson PM, Burnier M, Viigimaa M, et al. $2013 \mathrm{ESH} / \mathrm{ESC}$ Guidelines for the management of arterial hypertension. Eur Heart J 2013; 34:2159-2219.

22 The criteria committee of the New York Heart Association. Nomenclature and criteria for diagnosis of diseases of the heart and great vessels. Boston, MA The criteria committee of the New York Heart Association; 1994; 253-256.
23 Guyatt GH, Sullivan MJ, Thompson PJ, Fallen EL, Pugsley SO, Taylor DW, et al. The 6-minute walk: a new measure of exercise capacity in patients with chronic heart failure. Can Med Assoc J 1985; 132: 919-923.

24 Sung MM, Dyck JR. Age-related cardiovascular disease and the beneficial effects of calorie restriction. Heart Fail Rev 2012; 17:707-719.

25 Eckel R, York D, Rössner S, Hubbard V, Caterson I St, Jeor S, et al. Obesity, a worldwide epidemic related to heart disease and stroke: executive summary: AHA conference proceedings prevention conference VII. Circulation 2004; 110:2968-2975.

26 Hubert HB, Feinleib M, McNamara PM, Castelli WP. Obesity as an independent risk factor for cardiovascular disease: a 26-year follow-up of participants in the Framingham Heart Study. Circulation 1983; 67: 968-977.

27 Kenchaiah S, Evans JC, Levy D, Wilson PW, Benjamin EJ, Larson MG, et al. Obesity and the risk of heart failure. N Engl J Med 2002; 347:305-313

28 Wilson PW, D'agostino RB, Sullivan L, Parise H, Kannel WB. Overweight and obesity as determinants of cardiovascular risk: the Framingham experience. Arch Intern Med 2002; 162:1867-1872.

29 Jonsson S, Hedblad B, Engstrom G, Nilsson P, Berglund G, Janzon L. Influence of obesity on cardiovascular risk. Twenty-three-year follow-up of 22,025 men from an urban Swedish population. Int J Obes Relat Metab Disord 2002; 26:1046-1053.

30 McAllister RM, Delp MD, Laughlin $\mathrm{MH}$. Thyroid status and exercise tolerance. Cardiovascular and metabolic considerations. Sports Med 1995; 20:189-198.

31 Kahaly GJ, Kampmann C, Mohr-Kahaly S. Cardiovascular hemodynamics and exercise tolerance in thyroid disease. Thyroid 2002; 12:473-481.

32 Biondi B, Kahaly GJ. Cardiovascular involvement in patients with different causes of hyperthyroidism. Nat Rev Endocrinol 2010; 6:431-443.

33 Biondi B, Palmieri EA, Lombardi G, Fazio S. Effects of thyroid hormone on cardiac function - the relative importance of heart rate, loading conditions, and myocardial contractility in the regulation of cardiac performance in human hyperthyroidism. J Clin Endocrinol Metab 2002; 87:968-974.

34 Leonard J. Hyperthyroidism as a high cardiac output state. Am Heart J 1970; 79:265-275.

35 Polikar R, Burger AG, Scherrer U, Nicod P. The thyroid and the heart. Circulation 1993; 87:1435-1441.

36 Dörr M, Wolff B, Robinson DM, John U, Lüdemann J, Meng W, et al. The association of thyroid function with cardiac mass and left ventricular hypertrophy. J Clin Endocrinol Metab 2005; 90:673-677. 